\title{
O PATRIMÔNIO COMO EIXO ESTRUTURANTE DO DESENVOLVIMENTO? Os Planos de Ação e o PAC-CH em São Paulo
}

\section{HERITAGE AS A STRUCTURING AXIS FOR DEVELOPMENT? A study of PAC-CH in São Paulo.}

\author{
A. Marina Brandão \\ Faculdade de Arquitetura e Urbanismo; Universidade de São Paulo, Brasil \\ marina.brandao@usp.br
}

\begin{abstract}
RESUMO
O presente artigo pretende discutir as associações entre patrimônio e desenvolvimento no Brasil, a partir da participação de doze municípios paulistas no Programa de Aceleração do Crescimento - Cidades Históricas (PAC-CH). O programa apresentou duas fases distintas de implementação, sendo a primeira delas marcada pela realização dos Planos de Ação para as Cidades Históricas (2009-2010) como um instrumento para gestão integrada. Este foi estruturado com base nas demandas municipais, identificadas por meio da realização de diagnósticos e do levantamento de ações visando promover o desenvolvimento local, tendo o patrimônio como um eixo estruturante. A partir do levantamento do material produzido na primeira fase do PAC-CH, pretende-se discutir de que forma o conceito de desenvolvimento é mobilizado nas ações propostas pelos municípios e o quanto estas se relacionam com a ampliação da atuação do Iphan observada a partir dos anos 2000 , considerando um entendimento alargado do patrimônio.
\end{abstract}

Palavras-chave: patrimônio, desenvolvimento, IPHAN, São Paulo

Linha de Investigação: 2: Cidade e Ambiente.

Tópico: Patrimônio e paisagem cultural.

\section{ABSTRACT}

This article intends to discuss the associations between heritage and development in Brazil based on the participation of the twelve São Paulo municipalities in the Growth Acceleration Program - Historic Cities (PAC$\mathrm{CH})$. The program presented two distinct phases of implementation and included the "Action Plans for Historic Cities" in its first phase (2009-2010) as a management tool. Its structure was based on the municipal demands, through the identification of the cities main issues and the indication of potential actions designed for promoting local development, considering heritage as a structuring axis. Based on the analysis of the material produced in PAC-CH's first phase, the intention is to discuss the participation of São Paulo municipalities by examining how the concept of development is mobilized in the proposed actions and how much they relate to the expansion of Iphan's performance in the 2000s, considering a broad understanding of heritage. 


\section{SÃO PAULO15 17 LISBOA $25 \sim 26$ JUN 2020}

\section{O PAC-CH e os Planos de Ação no contexto de atuação do Iphan nos anos 2000}

A primeira década dos anos 2000 representou um momento de mudanças significativas no cenário político brasileiro, notadamente no que se refere ao patrimônio cultural. A partir dos anos $2000^{1}$, o Instituto do Patrimônio Histórico e Artístico Nacional (Iphan), órgão federal de preservação do patrimônio cultural do país, passou por uma redefinição de suas diretrizes, que orientaram as ações da instituição no anos seguintes. Destacam-se entre estas, "a participação social; a reinserção dos bens culturais na dinâmica social; a qualificação do contexto dos bens culturais; e a promoção do desenvolvimento local" (Figueiredo, 2014: 185).

Nesse contexto, observa-se a relevância dada à associação entre o campo do patrimônio e o conceito de desenvolvimento. Esta se traduziu na valorização da dinâmica local das cidades, extrapolando o tema do turismo, associação naturalizada a partir dos anos 1970, com a criação do $\mathrm{PCH}^{2}$, refletindo-se nas políticas realizadas pelo órgão. Do registro do patrimônio imaterial à realização dos inventários nacionais de referências culturais (INRC), ampliou-se, mesmo que ainda timidamente, o reconhecimento de diferentes formas de expressão de grupos sociais em diversas regiões do país. A proposta se enquadra na estratégia de atuação identificada por Dalmo Vieira ${ }^{3}$ como "Rede de Patrimônio", a partir de políticas que considerassem uma "visão ampla e abrangente do patrimônio de cada região" (Pereira, 2015: 53). Por sua vez, a partir desse reconhecimento mais amplo do patrimônio nacional, reforçou-se a possibilidade de que o patrimônio pudesse estar associado a iniciativas de geração de renda e empregos para os moradores, promovendo, dessa forma, o desenvolvimento a partir da valorização da memória e das práticas locais. As políticas do Iphan aparecem, então, alinhadas aos pilares de definição da "tridimensionalidade da cultura"4, termo utilizado pelo ex-ministro da cultura Gilberto Gil (2003-2008), em referência a seu caráter plural: econômico, cidadão e como vetor de desenvolvimento.

Nesse contexto, foi criada, em 2009, a linha "cidade históricas" no eixo Infraestrutura Social e Urbana do Programa de Aceleração do Crescimento (PAC) do Governo Federal. Lançado em 2007, sob tutela do Ministério do Planejamento Orçamento e Gestão, o programa tinha como objetivo, em linhas gerais, promover o crescimento econômico por meio do aumento dos gastos públicos, com investimento, sobretudo, em obras de infraestrutura. A presença do patrimônio, em um grande programa do governo federal, revelou a inclusão do patrimônio na agenda estratégica do governo federal.

O PAC-CH apresentou em sua implementação duas fases evidentes. A primeira se inicia em 2009, com o lançamento do programa e a chamada pública para elaboração dos Planos de Ação para as Cidades Históricas, com participação aberta para todos os municípios que contassem com bens tombados, registrados ou em processo de tombamento pelo Iphan. Os Planos pretendiam estabelecer um novo modelo de planejamento e gestão para o órgão, que considerasse as potencialidades locais e uma melhor articulação com os municípios e estados. A partir de 2013, o programa entrou em sua segunda fase,

\footnotetext{
${ }^{1}$ Sobre a atuação do Iphan nos anos 2000 ver Motta (2012) e Pissato (2018).

$2 \mathrm{O} \mathrm{PCH}$, Programa de Cidades Históricas foi um programa de investimento do governo federal entre 1973 e 1979 . Sobre o PCH ver Correa (2012).

${ }^{3}$ Dalmo Vieira foi diretor do Departamento de Patrimônio Material (DEPAM) do Iphan entre 2006 e 2011.

${ }^{4}$ Ver Brandão (2019).
} 


\section{SÃO PAULO15 $\sim 17 \cdot$ LISBOA $25 \sim 26$ JUN 2020

selecionando 44 cidades e 425 ações para o efetivo investimento, no âmbito do PAC-Il do Governo de Dilma Rousseff.

A proposta de elaboração dos Planos de Ação, na primeira fase do programa, apresentou uma leitura abrangente do patrimônio, considerando um planejamento integrado para "enfrentar os problemas estruturais das cidades históricas" (Iphan, 2009: 19). A proposta era que os Planos fossem pensados em conjunto com as esferas de governo e a com sociedade civil, contribuindo também para a construção de um Sistema Nacional do Patrimônio Cultural, em um esforço de melhorar a articulação entre as instâncias de gestão do patrimônio.

A partir de sua estruturação em etapas, sintetizadas no preenchimento de fichas pelas administrações locais, os Planos possibilitaram a leitura das principais demandas dos municípios participantes. Nas etapas orientadas pelo Iphan, cabia aos municípios: a elaboração de um diagnóstico, a indicação dos principais objetivos a serem alcançados considerando o prazo de quatro anos, além de proposta de ações com estimativa de recursos. Para tal, o Iphan divulgou uma cartilha que estabeleceu orientações para o preenchimento das fichas, incluindo a determinação de "eixos", sob os quais deveriam se encaixar as ações propostas pelos municípios. Os três eixos propostos pela cartilha do Iphan foram: 1. Produção de conhecimento e gestão da informação; 2. Planejamento e gestão; e 3. Dinamização e valorização do patrimônio cultural, contando com sub-eixos específicos dentro das categorias apresentadas. A análise individualizada das Linhas de Ação permitiu observar quais as principais demandas solicitadas pelos municípios, observando o entendimento do papel do patrimônio em sua estruturação.

A pesquisa se baseou em uma análise comparativa, buscando compreender quais as principais demandas indicadas. Cabe apontar, também, que o presente artigo se concentra na participação na primeira fase do programa, sem entrar na discussão da seleção das ações a partir de 2013, quando efetivamente foram realizados os investimentos pelo governo federal ${ }^{5}$.

\section{O estado de São Paulo no quadro do patrimônio: a participação dos municípios paulistas nos Planos de Ação}

O estado de São Paulo possuía, em 2009, segundo dados do Iphan, 76 bens tombados pela esfera federal, em 38 municípios. Desses municípios, treze submeteram material para a inscrição da Chamada Pública para elaboração dos Planos de Ação realizada pelo Iphan em maio de 2009: Cananéia, Carapicuíba, Cotia, Iguape, Iperó, Itu, Santana de Parnaíba, Santo André, Santos, São Bernardo do Campo, São Luiz do Paraitinga, São Sebastião e São Paulo. Como pré-requisito para a participação, todos os municípios que participaram do programa nessa etapa apresentam bens tombados, registrados ou em processo de tombamento ou registro pelo Iphan. Dos treze municípios, apenas três foram efetivamente contemplados com recursos a parir de 2013, na segunda fase do programa: Iguape, São Luiz do Paraitinga e Santo André.

Cada município entregou ao Iphan, em 2009, um conjunto de fichas, correspondente a cada uma das etapas dos Planos de Ação: 1. Levantamento Preliminar e Diagnóstico, 2. Objetivos e 3. Ações. Com o levantamento das ações foram assinados os Acordos de Preservação do Patrimônio Cultural (APPC). O artigo se baseia no material entregue na terceira etapa, que correspondeu à indicação das ações compreendidas como prioritárias para o investimento nos respectivos municípios. Cabe ressalvar nesse ponto que, apesar da sua

\footnotetext{
${ }^{5}$ Para análise dos três municipios paulistas seleccionados ver Brandão (2020, no prelo).
} 


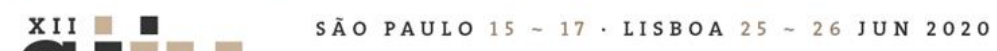

Seminário Internacional de Investigação em Urbanismo

Seminario Internacional de Investigación en Urbanismo

participação na fase de levantamento preliminar e diagnóstico, o município de São Paulo não levou adiante a participação na etapa dos Planos de Ação por questões políticas, e por esse motivo a capital não foi incluída na pesquisa.

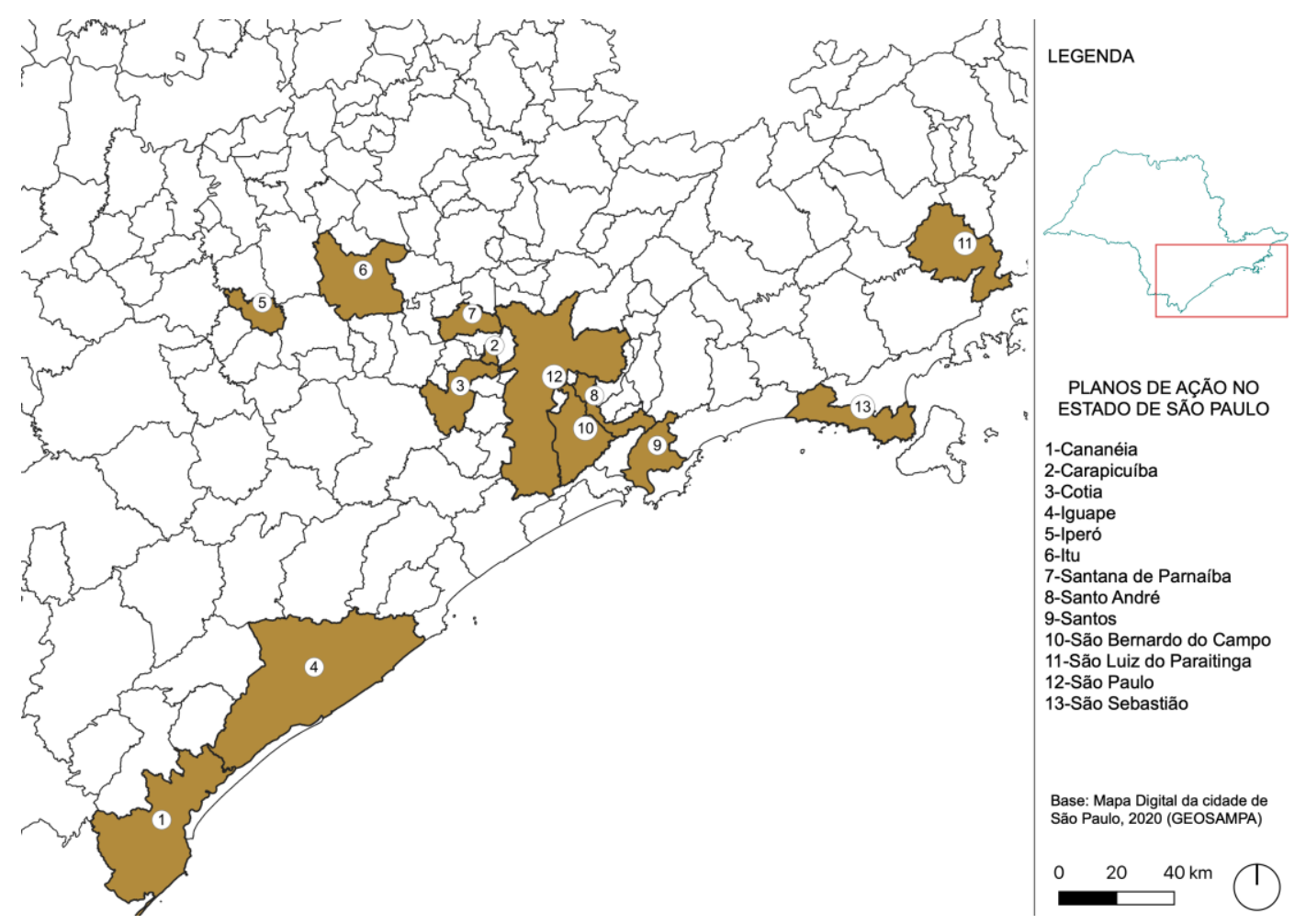

Mapa 01 Planos de Ação no estado de São Paulo. Elaboração própria a partir das Fichas dos Planos de Ação (IPHAN/DPE)

O Gráfico 01 sintetiza a leitura comparativa das fichas da terceira etapa dos Planos de Ação. A partir dessa análise, observa-se que as demandas municipais, de forma geral, priorizaram o item 3. Dinamização $e$ valorização do patrimônio cultural, com $23 \%$ das ações correspondendo ao item 3.1 Recuperação e uso do patrimônio cultural, categoria sob a qual foram solicitadas as restaurações de edificações. De modo geral, o item 1. Produção de Conhecimento e Gestão da Informação foi o menos priorizado nas ações, contando apenas com uma pequena parcela (5\%). No item 2. Planejamento e Gestão, somando as 3 linhas chega-se a $14 \%$, o que se configura como uma parcela muito pequena diante do quadro geral. 


\section{SÃO PAULO15 $\sim 17 \cdot$ LISBOA $25 \sim 26$ JUN 2020

treinamento de guias locais para ecoturismo e a criação de instrumentos/equipamentos de educação patrimonial, considerando o patrimônio imaterial. Chama a atenção que os projetos não estão restritos ao centro histórico, tendo propostas de articulação no território do município, bem como com outras cidades próximas, como no roteiro turístico "Taipa de Pilão". Cabe apontar, também, que novamente o embutimento de rede elétrica aparece como uma solicitação, indicado no eixo 3.2 Requalificação urbanística.

No caso de Cotia, por exemplo, destacaram-se as ações relacionadas à formação de técnicos e a criação de Conselho de Patrimônio, objetivando o aperfeiçoamento das políticas públicas de desenvolvimento local. Observou-se, também, que as ações indicadas não se limitaram apenas ao entorno dos bens tombados. As demandas solicitadas equalizam melhorias voltadas para o desenvolvimento do turismo na região, com ações de fortalecimento de gestão. O turismo apareceu como um dos objetivos indicados, a partir da proposta de melhorias de infraestrutura para o Sítio Padre Inácio, como a instalação de receptivo turístico e requalificação da estrada de acesso. Associa-se a esse objetivo, também, a capacitação de monitores culturais para receptivo à visitação. Reforçando o entendimento da solicitação das ações para além dos bens tombados, destaca-se a proposta de implantação de Parque Linear na margem do Rio Cotia, contando com espaços de lazer e esportes, incluindo a construção de um centro esportivo, programado para utilização durante a Copa Mundial de Futebol de 2014 no Brasil.

Em Iperó, assim como Cotia, observou-se a diversidade de ações propostas, em uma área de atuação que extrapola o bem tombado (Real Fábrica de Ferro de São João), abrangendo também o pátio ferroviário e o centro histórico. A ações incluíram projetos e obras relacionados ao restauro da Real Fábrica de Ferro de São João de Ipanema e, também, temas referentes à requalificação urbanística, incluindo projeto e obra de assentamento e nivelamento das ruas do Centro Histórico, assim como a construção de equipamento urbano para transposição do leito ferroviário entre o centro e o bairro. As demandas incluíram também a criação de Fundo Municipal para recuperação de imóveis privados, de um Conselho Municipal de Patrimônio e de uma parceria com Secretaria de Educação (municipal e estadual). Destaca-se, ainda, a aplicação do INRC e a capacitação de servidores para realização de atividades educativas sobre patrimônio histórico e cultural do município. Chamou a atenção, também, a proposta de execução de restauro do conjunto ferroviário de Iperó, com reutilização de vagões e pátio, tendo como objetivo específico a revitalização do patrimônio ferroviário da Estrada de Ferro Sorocabana no Município de Iperó "para usos socioculturais". É interessante a comparação com Itu, que também apresenta proposta de restauração do patrimônio ferroviário, tendo como justificativa o aumento do turismo. É evidente que o "uso sociocultural", como indicado por Iperó, não exclui a possibilidade de fortalecimento da indústria turística. O que se ressalta é a forma como a ação é enquadrada no contexto de preenchimento da ficha, observando uma intenção mais abrangente na elaboração da proposta.

Conforme observado no Gráfico 01, Santos considerou uma grande diversidade de propostas. O município foi o que solicitou o maior número de ações. Estas, de abrangência municipal, incluíram restauração, projetos sociais e obras de requalificação urbanística. A intensa participação de Santos nessa etapa se relaciona com a maior estrutura municipal para a gestão do patrimônio, considerando que o município conta, desde 1989, com a atuação do Conselho de Defesa do Patrimônio Cultural de Santos (CONDEPASA). O maior volume de ações se dá, também, pois os técnicos responsáveis pelo preenchimento das fichas consideraram para cada tema o projeto e a execução separadamente. 


\section{SÃO PAULO15 $\sim 17 \cdot$ LISBOA $25 \sim 26$ JUN 2020

As ações solicitadas por Santos se mostram coerentes com os problemas e potencialidades apontados no diagnóstico. Entre as ações apresentadas, destacaram-se o número de ações destinadas à "recuperação da qualidade dos espaços públicos", entre as quais: o já mencionado embutimento de fiação elétrica, a criação de mobiliário urbano e a criação de novos usos para os espaços públicos, utilizados pela população como forma de lazer. Aliada à recuperação dos espaços públicos, foi possível identificar nas ações a criação de programas para incentivar o uso da área central como alternativa de lazer para a população, a partir da reativação de edificações.

Outro objetivo que se destacou foi a proposta de recuperação dos edifícios privados com uso relacionado com habitação de interesse social, como na proposta de implementar o "Programa Alegra Centro Habitação", de incentivo à reabilitação de imóveis encortiçados, com a criação de novas unidades habitacionais para venda e locação, além da realização de registro das famílias vivendo em cortiços na região central, tema que apareceu com bastante ênfase no diagnóstico realizado na primeira etapa. Ainda sobre habitação, cabe ressaltar como uma das ações propostas por Santos o financiamento de imóveis privados, a partir da criação de uma linha de financiamento específico.

Também no litoral paulista, São Sebastião se enquadrou nos municípios que apresentaram ações diversificadas. Assim como observado no levantamento diagnóstico, as ações têm como área de estudo o Bairro de São Francisco da Praia e o centro histórico. O município foi o segundo com maior número de ações solicitadas, sendo a maioria destas correspondendo aos itens 3.2 Requalificação urbanística e 3.6 Difusão e Promoção do Patrimônio Cultural. Destacaram-se, entre essas, as ações voltadas para a melhoria da qualidade ambiental, como a operação caça esgoto, e a realização de obras e projetos de requalificação de praças. O INRC aparece novamente como uma proposta de ação, tendo como objetivo "consolidar e sociabilizar os produtos culturais", enquadrado no item 3.6 Difusão e Promoção do Patrimônio Cultural. Ainda enquadradas sob eixo, destaca-se a implantação de "ações que transformem o Centro Histórico como elemento aglutinador de identidades", como a execução do "Projeto Identidade Caiçara", valorizando a linguagem, memória e histórias dos moradores da região. O eixo ainda contemplou as ações de profissionalização do comércio existente voltado para o turismo incentivando serviços diversos, a partir da implementação de cursos profissionalizantes e treinamentos para população local. Por fim, cabe apontar também a viabilização do convênio entre Caixa Econômica Federal e proprietários para a recuperação de imóveis privados, enquadrados no eixo 3.4 Financiamento para a recuperação e promoção de usos de imóveis privados.

Em Cananéia, assim como em São Sebastião observou-se a diversidade das ações propostas, passando pelo fortalecimento institucional, restauro de edificações e requalificação urbanística. Observou-se, também, como o perímetro de atuação proposto extrapolou o centro histórico. Entre as ações diversas identificadas na leitura da ficha, destacaram-se a criação da Secretaria de Cultura do município, a implantação de programa de educação patrimonial na grade curricular do Ensino Básico e a criação do Fundo Municipal para recuperação de imóveis privados. É oportuno observar como os técnicos responsáveis pelo preenchimento da ficha enquadraram a restauração de diversos edifícios como uma única ação, estratégia oposta de Santos, que individualizou não só as edificações, mas também os estágios de execução.

Ainda na ficha de Cananéia foi possível observar as demandas relacionadas à requalificação do espaço público e à difusão e promoção do patrimônio cultural. Entre essas, destacam-se: o embutimento da fiação, a aplicação do INRC, incluindo a identificação e mapeamento das casas de farinha e cozinhas caiçaras, 


\section{SÃOPAULO15 17 LISBOA $25 \sim 26$ JUN 2020}

artesanato regional e a pesca artesanal. Sobre as demandas relacionadas ao turismo, ressalta-se novamente o tema da capacitação da população e da valorização da produção local. Nesse sentido, apareceram como ações na ficha de Cananéia a formação de monitores locais voltados para o turismo cultural e a "identificação de elementos do patrimônio imaterial que possam colaborar com ações de desenvolvimento socioeconômico" (Iphan, 2009), com apoio à estruturação de atividades produtivas, com ênfase para as atividades tradicionais.

No caso de São Bernardo do Campo, as demandas foram todas pensadas para a viabilização de um único projeto. A proposta seria a implementação de um centro de atividades ligadas ao audiovisual no Pavilhão e Estúdios da antiga Cia. Cinematográfica Vera Cruz. Considerando a deficiência de equipamentos de cultura apontada pelo município no diagnóstico da primeira etapa, a demanda é válida, mas certamente não explorou a potencialidade do programa, identificada pela diversidade das linhas de ação propostas na cartilha. A concentração das ações em um único projeto pode ser lida como uma estratégia, baseada no financiamento de um projeto único, sem a garantia de sua continuidade. Considerando o perfil traçado para São Bernardo do Campo, que possui um PIB elevado, um Conselho Municipal de patrimônio atuante desde os anos 1980, e projetos como o inventário do patrimônio cultural e ambiental, esperava-se que as ações solicitadas apresentassem a mesma tendência observada em municípios como Cotia e Iperó, com maior diversidade e abrangência territorial das ações. Entende-se que, talvez, justamente pela presença de uma estrutura municipal de patrimônio, a participação no programa tenha se dado de forma estratégica, concentrando todos os recursos em um único projeto.

Em Santo André, 57\% das ações solicitadas se enquadram no eixo 3.1 Recuperação e uso do patrimônio cultural. As demais correspondem ao Item 3.2 Requalificação urbanística (36\%), sendo apenas $7 \%$ ao item 3.5 Fomento as atividades produtivas locais, que corresponde a uma única ação. Observou-se como a maior parte das ações indicadas se localizam na Parte Baixa da Vila de Paranapiacaba, em consonância com os critérios observados no tombamento da Vila pelo Iphan, que se baseou muito mais nos critérios estilísticos, excluindo, desse modo, a chamada Parte Alta, que apresenta ocupação com traçado irregular, concentrando a maior parte da população residente local. A maioria das ações indica a necessidade de restauro das edificações, considerando a realização de projeto e da obra. A única ação não relacionada à execução de projeto ou obra foi a indicação de um curso para formação de restauradores, mas que está indiretamente relacionada ao processo de recuperação material da Vila. Nesse sentido, as ações indicadas dos Planos de Ação de Santo André anteciparam o PAC-CH a partir de 2013, se estruturando como uma lista de prioridades destinada para elaboração de projetos e obras em edificações. 


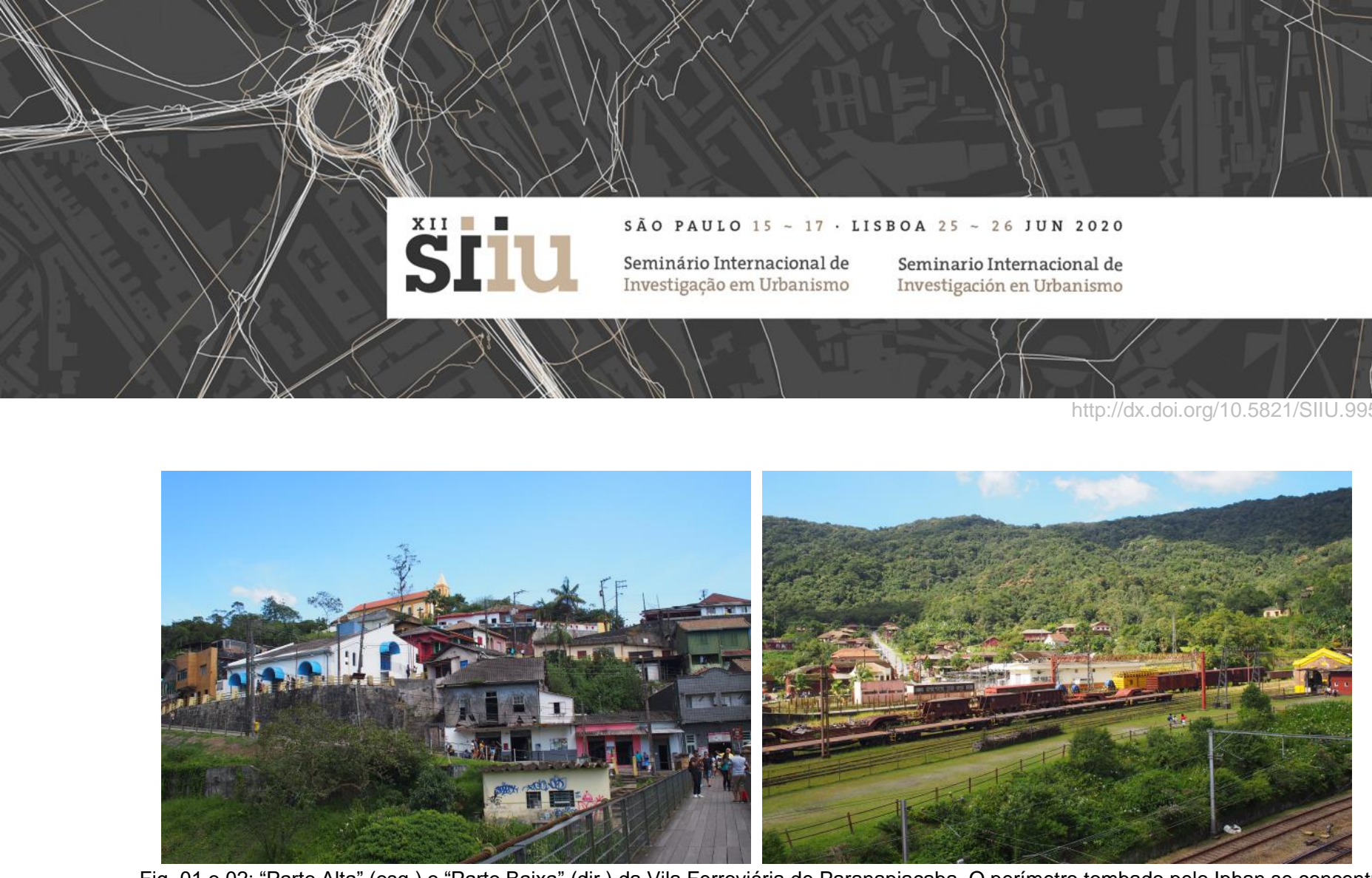

Fig. 01 e 02: "Parte Alta" (esq.) e "Parte Baixa" (dir.) da Vila Ferroviária de Paranapiacaba. O perímetro tombado pelo Iphan se concentra na Parte Baixa, com traçado ortogonal e edificações em madeira, herança da ocupação inglesa da Vila. (Arquivo pessoal, 2019)

Já as Linhas de Ação indicadas por São Luiz do Paraitinga na terceira etapa do PAC-CH priorizaram a recuperação da cidade após a enchente do Rio Paraitinga em janeiro de 2010, destruindo um grande número de imóveis, entre eles a Igreja da Matriz. Por esse motivo, as duas principais linhas consideradas foram, respectivamente, 3.3 Infraestrutura urbana e social e 3.2 Recuperação Urbanística. Além das demandas relacionadas diretamente à recuperação das edificações atingidas, é oportuno observar como algumas destas extrapolaram a questão, considerando também temas como turismo, fortalecimento da gestão e a instalação de novos equipamentos para a cidade. Sobre o tema da gestão, especificamente, cabe destacar a indicação da aplicação do INRC para o município, a instalação de escritório técnico para auxílio na gestão, licenciamento e fiscalização nos três níveis de governo e a capacitação de servidores municipais para patrimônio cultural.

No caso de Iguape, cidade litorânea do Vale do Ribeira, as ações indicadas apresentaram uma grande diversidade nas linhas de ação enquadradas. Identificou-se nas ações a recorrência de alguns temas, relevantes para a pesquisa por se relacionarem às estratégias de compatibilização entre patrimônio e desenvolvimento nos anos 2000. Algumas das ações indicadas se relacionam com as atividades atribuídas a temas relacionados à gestão, como a criação de um Fundo Municipal para recuperação de imóveis privados e a instalação de um escritório técnico para auxílio na gestão, licenciamento e fiscalização nos três níveis de governo, dialogando com as ideias do SNPC. Outro eixo explorado na elaboração dos Planos de Ação de Iguape foi a questão da geração de renda, revelando assim aproximações com o discurso do Iphan nos anos 2000. O tema inclui o turismo cultural e ambiental, tratando da capacitação de agentes locais, da sinalização turística, da qualificação dos espaços destinados à produção e venda de artesanatos e da produção de um Guia Turístico do Município. Além disso, cabe apontar que as ações indicadas não se restringem ao "centro histórico", mas apresentaram abrangência municipal, incorporando, também, outros elementos da paisagem do município, como o Morro do Espia e o Mar Pequeno, incorporados na poligonal tombada pelo Iphan em 2009.

\section{Patrimônio como vetor do desenvolvimento?}




\section{SÃO PAULO15 $\sim 17 \cdot$ LISBOA $25 \sim 26$ JUN 2020

A leitura das fichas dos municípios envolvidos na elaboração dos Planos de Ação em São Paulo âmbito do PAC-CH, em sua primeira fase, permitiu traçar algumas análises, considerando não só a natureza das ações indicadas, mas também a visão do próprio Iphan nos anos 2000.

A questão da restauração das edificações apareceu como a principal demanda entre as linhas de ação indicadas. Observou-se, porém, como a justificativa associada à solicitação das ações foi diversa, sendo em alguns casos associadas a obras emergenciais (Carapicuíba e São Luiz do Paraitinga), em outros, a iniciativas de estímulo à visitação e ao turismo (Itu e Santo André), em projetos pontuais com usos específicos (São Bernardo do Campo) e em outros apresentados de forma mais abrangente relacionados a outras ações (Cotia, Santana de Parnaíba, Iperó, Iguape, Santos, São Sebastião e Cananéia).

As fichas de diagnóstico dos município revelaram que, em muitos casos, as edificações encontravam-se em estágio avançado de degradação material, configurando-se como uma demanda básica para garantir sua integridade física. Municípios como Carapicuíba, que apresentam poucos recursos (financeiros e técnicos) para o patrimônio, diante de uma possibilidade de investimento, os pedidos foram condizentes com as propostas de recuperação das edificações. É importante apontar, também, que foi a primeira vez que um programa de alcance nacional dedicado ao patrimônio cultural chegou aos municípios paulistas mencionados, mesmo sem o efetivo repasse de verba, que só veio em 2013, com o lançamento do PAC II em Iguape, Santo André e São Luiz do Paraitinga, no estado de São Paulo.

Observou-se, também, como na maioria dos municípios identificados prevaleceu uma leitura com demandas mais abrangentes. Estas consideraram não apenas o investimento no restauro de edificações, mas também instrumentos que se relacionam com a atuação do Iphan a partir dos anos 2000, como o financiamento para a recuperação de imóveis privados, a realização de inventários nacionais de referências culturais e a criação de Fundos Municipais de Patrimônio. Nesse sentido, os municípios acataram o entendimento alargado de patrimônio como um eixo para o planejamento, proposto pelo Iphan na chamada pública do PAC-CH em 2009.

Em experiências anteriores, no Brasil e em outros países da América Latina, as políticas de patrimônio associadas ao desenvolvimento tiveram em sua abordagem uma estreita associação com o binômio "patrimônio + turismo". O que se observou nas políticas federais de patrimônio no Brasil, entre a primeira década dos anos 2000 e meados da segunda, foi a reafirmação do entendimento de que essa abordagem não é suficiente para a inserção do patrimônio em uma agenda de desenvolvimento.

A forma como a primeira fase do $\mathrm{PAC}-\mathrm{CH}$ foi idealizada revelou um interesse do órgão em propor um instrumento de planejamento articulado, no qual o patrimônio é parte indissociável da cidade, de seu contexto e da sua relação com as dinâmicas locais. Parte-se da compreensão de que patrimônio é o conjunto de práticas, lugares e objetos de interesse para preservação, seja por seus valores histórico, documental, afetivo, entre outros. Nesse sentido, o dito "patrimônio material" é compreendido como suporte para a vida cotidiana, ao mesmo tempo em que contribui para a construção e afirmação de identidade. A importância da dimensão local do patrimônio o torna fundamental no entendimento das políticas de planejamento urbano, que ocorrem, obrigatoriamente, em uma escala menor, mais próxima das dinâmicas próprias que configuram as diferentes formas de viver e ocupar determinado território.

Entende-se que o conceito de desenvolvimento permite diversas associações, sendo algumas mais restritivas, compreendidas como sinônimo de crescimento econômico, e outras mais alargadas, incluindo 


\section{SÃOPAULO15 $17 \cdot$ LISBOA $25 \sim 26$ JUN 2020}

questões sociais e culturais. De modo geral, é possível interpretar que o termo é mobilizado na elaboração dos Planos de Ação extrapolando a ideia de crescimento econômico, muito em função da estruturação que foi dada ao programa pelo Iphan, a partir da indicação das linhas de ação. Estas, considerando a multiplicidade de áreas de atuação presente nos eixos propostos, reforçaram o discurso do Iphan sobre o significado de patrimônio na contemporaneidade, a partir de sua compreensão como um vetor para o desenvolvimento, considerando a valorização das práticas e da memória local, bem como sua relação com o planejamento urbano, objetivando a melhoria da qualidade de vida de seus habitantes.

\section{BIBLIOGRAFIA}

BRANDÃO, M. (2020, no prelo). Patrimônio na agenda do desenvolvimento e o PAC-CH em São Paulo: estratégias e debates nos anos 2000. Dissertação de mestrado. Faculdade de Arquitetura e Urbanismo da Universidade de São Paulo. - (2019). O IPHAN nas políticas culturais da Era Lula: A "tridimensionalidade da cultura" e as políticas de recuperação dos centros históricos. In Anais XVIII ENANPUR XVIII. Natal

CARMO, B. (2019) PCH, Programa Monumenta e PAC-HC: o patrimônio cultural na perspectiva de política pública. Dissertação de mestrado. São Paulo: Instituto de Arquitetura e Urbanismo da Universidade de São Paulo.

CORREA, S. (2012) O Programa de Cidades Históricas (PCH): Por Uma Política Integrada de Preservação do Patrimônio Cultural - 1973/1979. Dissertação de Mestrado. Faculdade de Arquitetura e Urbanismo da Universidade de Brasília.

FIGUEIREDO, V. (2014) Da Tutela dos Monumentos à Gestão Sustentável das Paisagens Culturais Complexas: Inspirações à política de preservação cultural no Brasil. Tese de Doutorado. São Paulo: Faculdade de Arquitetura e Urbanismo da Universidade de São Paulo.

LEAL, S. (2017). PAC-cidades históricas: implicações e repercussões de uma política pública federal de preservação. Dissertação de mestrado. Minas Gerais: Faculdade de Arquitetura e Urbanismo da Universidade Federal de Minas Gerais.

MINISTÉRIO DA CULTURA/IPHAN. (2009). Planos de Ação para Cidades Históricas - Patrimônio Cultural e Desenvolvimento Social: Construindo o Sistema Nacional de Patrimônio Cultural. Brasília: Edições IPHAN.

MOTTA, Lia. (2012) Notas sobre o IPHAN na década de 2000. In ANDRADE, Rodrigo Melo Franco de. Brasil: Monumentos Históricos e Arqueológicos (317-328). Rio de Janeiro: IPHAN/DAF/COPEDOC.

PEREIRA, D. (2015) Cidades patrimônio: uma geografia das políticas públicas de preservação no Brasil. Dissertação de mestrado. Faculdade de Filosofia, Letras e Ciências Humanas da Universidade de São Paulo.

PISSATO, C. (2018) Tombamento e gestão em Iguape/SP: políticas do patrimônio cultural nos anos 2000. Dissertação de mestrado. Faculdade de Arquitetura e Urbanismo da Universidade de São Paulo. 